\title{
Application of Mindfulness for Internal Characteristics Treatment in Adults Who Stutter
}

\author{
DoRyeon $\mathrm{HeO}^{1}$, WhaSoo Kim² \\ 'Diagnosis-Assessment Center, Daegu University, Daegu, Korea \\ ${ }^{2}$ Department of Speech Language Pathology, Daegu University, Daegu, Korea
}

말더듬 성인의 내면적 특성 치료를 위한 마음챙김 적용

허 도 련'김 화 수 ${ }^{2}$

대구대학교 진단평가센터', 대구대학교 언어치료학과 ${ }^{2}$

\begin{abstract}
Purpose: Most stuttering adults use strategies to escape and avoid stuttering to solve stuttering. Those strategies make it more difficult to solve stuttering rather than cure it. The present study aimed to examine how to apply mindfulness as a technique to accept stuttering. Methods: As materials Korean version of the Mindfulness-Based Stress Reduction (K-MBSR), Mindfulness-Based Cognitive Therapy (MBCT), Dialectical Behavior Therapy (DBT), Acceptance \& Commitment Therapy (ACT) for measuring the mindfulness and for applying principles to the treatment of stuttering were used in the study. Results: K-MBSR's mindfulness meditation, MBCT's automatic adjustment status, DBT's dialectical counseling skills, creative despair induction in ACT, and program metaphors were summarized as three stages. Each step corresponded to the motivation of treatment, the introduction of correct method, and meditation practice of mindfulness. The key to these three steps is to allow the stutterer to accept stuttering. Conclusion: Stuttering behavior therapy programs are used externally to remove stuttering. Internally, it accepts stuttering. If we look at stuttering based on the principle of mindfulness, the stuttering problem gets worse as they reject stuttering. The therapist can use the programs in stuttering counseling to solve this problem.
\end{abstract}

Key Words: Stuttering adults, Mindfulness, Internal characteristics, Stuttering therapy.

Received: January 18, 2018 / Revised: March 23, 2018 / Accepted: April 9, 2018

Correspondence: DoRyeon Heo, Diagnosis-Assessment Center, Daegu University, 33 Seongdang-ro 50-gil, Nam-gu, Daegu 42400, Korea

Tel: +82-53-650-8097 / E-mail: hdr7788@naver.com

\section{INTRODUCTION}

말더듬은 크게 겉으로 드러나는 말더듬 행동과 내면화된 요 소의 두 부분으로 살펴볼 수 있다. 말더듬 치료 또한 말더듬 행 동에 대한 접근(Kim \& Kwon, 1994; Kwon \& Lee, 2004)과 내면화된 요소의 접근으로 나눌 수 있다. 말더듬 성인의 내면 화된 요소에 관한 연구들을 살펴보면 말더듬인의 자아 증진에 관한 Jeon \& Kwon(2005)의 연구, 행동인지 말더듬 치료 프로 그램을 적용한 Jang \& Kwon(2005)의 연구, 게슈탈트 치료를 적용한 연구(Ko \& Kwon, 2008) 등이 있다. 마음챙김은 팔리 어 sati의 영어 번역이다. Sati는 알아차림과 기억이라는 의미를 갖고 있다. 마음챙김 명상에 기반한 스트레스 감소(Mindfulness-Based Stress Reduction, MBSR) (Kabat-Zinn, 1982) 프 로그램을 개발한 Kabat-Zinn(2003)의 정의를 살펴보면, 마음
챙김이란 특별한 방식으로 주의를 기울이는 것을 말하고, 현재 순간에 펼쳐지는 경험을 비판단적으로 의식하는 것이다. 즉 현 재 순간을 비판단적으로 알아차려야 함을 기억하라는 것이라 할 수 있다. 최근 마음챙김(mindfulness)에 기반한 3세대 인지 행동치료가 등장함에 따라 다양한 분야에서 이러한 흐름이 영 향을 미치고 있다(Cho, 2016; Je, 2016; Lee, 2016). 심지어 IT 기업인 Google에서도 직원들을 대상으로 마음챙김을 응용한 명상 프로그램을 자체 개발하여 운영하고 있는 실정이다(Tan, 2012). 말더듬 치료 또한 예외일 수 없는데, 최근의 국외 말더듬 관련 논문들에서도 이러한 흐름을 살펴볼 수 있다(Beilby et al., 2012; Boyle, 2011; de Veer et al., 2009; Plexico \& Sandage, 2011). 국내에서도 마음챙김에 기반한 치료 논문과 서적들이 다수 출판되어 있지만, 말더듬 분야에서는 현재 $\mathrm{HeO}$ et al.(2016)의 연구를 제외하고 없는 실정이다. 
어떠한 생각이 일어난다면 이는 현실이 아닌 단지 그러한 생 각일 뿐이다. 따라서 관련된 정서를 회피하거나 제거하기 위한 행동을 할 필요가 없게 된다. 기존의 인지행동치료에서는 불안, 초조, 두려움 등의 표적 행동을 수정하기 위해 다양한 노력을 기울인다. 사실 외적으로 노력해서 해결되는 문제도 있지만, 이 러한 문제들이 전부 노력해서 해결된다고 볼 수는 없다. 오히 려, 어떤 측면에서는 노력하지 말아야 해결되는 문제가 있다. 이 러한 점에서 기존의 방법을 보완하여 등장한 것이 마음챙김에 기반한 치료 프로그램들이다. 이 중 하나인 수용-전념 치료 (Acceptance \& Commitment Therapy, ACT) (Hayes et al., 1999)에서 '오렌지 생각하지 말기'라는 메타포가 있다. 우리가 오렌지를 생각하지 않으려 최선을 다해 노력하면 노력할수록 오히려 오렌지가 더욱더 생각나게 된다는 것이다. 이러한 원리 는 우리가 평소 느끼는 불안, 초조 등에도 적용 가능하다. 한 가지 예로, 많은 사람 앞에서 발표를 할 때 내면적으로 불안해 하지 않으려 노력한다면 오히려 불안감은 더욱 커지게 될 것이 다. 이와 마찬가지로 말더듬 성인이 말을 더듬지 않으려 시도하 는 도피 및 회피 전략 또한 말더듬을 해결해 주기보다는 오히 려 말더듬을 악화시키는 경우가 대부분이다. ACT의 발달 배경 인 정상성 가설(Hayes at al., 1999)을 살펴보면, 이는 기존의 정상이라는 개념에 의문을 던지고, 새로운 정상에 대한 개념을 소개하는 이론이다. 건강한 상태가 정상이고 질병에 걸린 상태 가 비정상인 것이 기존의 정상이라는 관점이다. 그러나 $\mathrm{ACT}$ 에 서는 먼저 고통이 인간에게 보편적으로 나타나는 현상이라는 사실을 인정하고 시작한다. 즉 만약 이러한 상태가 지금 존재 한다면, 이를 정상이라고 보는 것이다. 이 가설로 말더듬 현상 을 살펴보면, 만약 말을 더듬는 현상이 나타난다면 그것은 정 상적인 현상이라고 할 수 있다. 그러나 대부분의 말더듬인들에 게서 말더듬은 비정상이고, 제거되어야 할 대상으로 인식하고 있기 때문에 이를 제거하려고 노력한다. 그리고 제거하려 노력 하면 할수록 Sheehan(1986)이 제시한 말더듬 빙산의 해수면 아랫부분이 더욱 커지게 되고, 끊임없이 말더듬에 도피 및 회 피하게 되는 악순환이 반복된다. 이 현상은 $\mathrm{ACT}$ 에서는 경험 회피라는 용어를 사용하여 표현하고 있다(Hayes at al., 1996). 마음챙김에 기반한 프로그램들 중 하나인 변증법적 행동치료 (Dialectical Behavior Therapy, DBT) (Linehen, 1987)에서는 경계선 인격장애인들에게 수용 혹은 변화를 요구한다. 삶에서 만나는 여러 상황에서 내담자는 각 상황에 맞는 적절한 행동 을 취해야 한다. 그러나 이러한 방법을 찾지 못하면 내담자의 역기능적인 행동 패턴으로 인한 문제들이 발생하게 된다고 본 다. 따라서 상담가는 내담자가 정(thesis), 반(antithesis)의 변증 법적 갈등을 절충하여 합(synthesis), 즉 해결-초점적 전략을 찾을 수 있도록 유도한다. 이러한 측면에서 마음챙김이 부정적
인 상위 인지를 감소시키고 수용적인 측면을 증가시키는 효과 가 있으므로(Williams, 2008), 이 원리를 말더듬 분야에 적용 한다면 유용할 것이다.

말더듬 성인에게 마음챙김을 적용하기 전에, 먼저 말더듬 치 료의 목적에 대해 고찰할 필요가 있다. 말더듬인을 중재할 때의 궁극적인 목적이 행복한 말더듬인(happy stutterer)을 만드는 것이라 볼 수는 없을 것이다. 최종 목적은 말더듬 성인이 자발 적인 유창성(spontaneous fluency)을 습득하는 것이다. 그 방 법으로 말더듬 행동치료를 실시하는 것이 외적인 말더듬 행동 중재 방법이고 마음챙김은 말더듬 성인이 말더듬을 대할 때의 자세, 즉 내적인 중재 방법의 일환으로 사용할 수 있다. 일반적 으로 말더듬 행동치료를 통해 말더듬을 줄이면 의사소통에 대 한 부정적인 태도 또한 감소하게 된다(Ingham, 1984). 물론 말 더듬 치료가 효과적으로 실시되려면 불안, 태도 등에도 접근해 야 한다는 주장도 있지만(Guitar, 1998), 말더듬인의 부정적 태 도와 불안을 해결하기 위한 가장 좋은 방법은 유창하게 말하 는 능력을 제공하는 것이다(Ryan \& Ryan, 1995). 따라서 말더 듬을 소거하기 위해서는 말더듬 행동치료를 실시하되, 마음챙 김을 통해 말을 오래 더듬어 온 말더듬 성인의 의사소통에 대 한 부정적인 태도, 도피 및 회피 전략 등에 접근하는 방법이 더 욱 효과적이라고 볼 수 있다.

이러한 문제들을 포괄하여, 본 논문에서 말더듬 성인의 치료 에 실제적으로 마음챙김을 적용하는 방안에 관하여 고찰하려 한다. 이를 위해 현재 심리학 영역에서 마음챙김 원리를 적용하 여 개발된 대표적 프로그램들인 한국형 마음챙김 명상에 기반 한 스트레스 감소(Korean version of MBSR, K-MBSR) (Chang et al., 2007), 마음챙김에 기초한 인지치료(Mindfulness-Based Cognitive Therapy, MBCT) (Segal et al., 2002), DBT, ACT 프로그램들에 대하여 살펴볼 것이다. 이는 마음챙김의 원리를 각 치료 목적에 맞도록 어떻게 프로그램화 하였는지 살펴보는 것에 의의가 있다. 마지막으로 마음챙김을 말더듬인에게 적용 하기 위한 방법에 대해 고찰해 보고자 한다.

\section{MATERIALS AND METHODS}

\section{마음챙김에 기반한 4 가지 치료 프로그램}

\section{K-MBSR}

K-MBSR은 스트레스 감소를 목적으로 Kabat-Zinn(1982)이 개발한 MBSR을 Chang(2007)이 국내용으로 번안한 프로그램 이다. 1 회기는 내담자에게 마음챙김에 대해 소개하고, 마음챙 김의 7가지 태도인 판단하지 않음(non-judgment), 인내심(patience), 초심(beginner's mind), 믿음(trust), 애쓰지 않음(non- 
striving), 받아들임(acceptance), 내려놓음(letting-go)의 개념 에 대해 소개한다. 그 다음 건포도 명상과 바디 스캔을 실습한 다. 건포도 명상은 건포도를 마치 처음 보는 것처럼 세심히 관 찰하고, 건포도를 먹을 때 발생하는 촉각, 미각 등의 감각들에 주의를 기울이는 것이다. 바디 스캔은 신체 내부에 주의를 기 울이며 발생하는 감각을 느끼는 방법이다. 2 회기는 바디 스캔 의 뜻과 의미, 실시 방법을 소개하고, 걷기 명상과 바디 스캔을 실습한다. 3회기는 호흡을 관찰하는 방법을 소개하고, 바디 스 캔과 호흡 훈련을 실습한다. 4회기는 호흡 확장을 통하여 현재 순간을 비판단적으로 의식하고 자각하는 방법을 소개하고, 호 흡 훈련과 정좌 명상을 실습한다. 5 회기는 마음을 있는 그대로 관찰하며 수용하는 방법을 소개하고, 정좌 명상을 실습한다. 6 회기는 하타 요가 동작을 하면서 호흡과 감각에 깨어 있는 훈 련을 실시한다. 7 회기는 마음챙김 종일 명상 수련으로, 먹기 명 상을 포함하여 6 7시간 동안 묵언 수행을 하며 현재 순간을 자 각하는 훈련을 한다. 8 회기는 마음챙김 명상에 대한 소감 및 자신만의 명상법을 이야기하고 리뷰하는 시간을 갖는다. 이 KMBSR 프로그램의 과정을 요약하여 Figure 1에 제시하였다.

\section{MBCT}

MBCT는 MBSR을 바탕으로 Segal et al.(2002)이 인지치료 로 재구성한 프로그램이다. 이 프로그램은 특히 우울증 재발 방지에 초점을 두어 개발되었다. 국내에서는 우울증 환자들을 대상으로 한 Jeon(2010)의 연구, 스마트폰 중독 경향 대학생들 을 대상으로 한 Son(2018)의 연구 등이 있다. 1 회기는 자신의 삶에서 무슨 일이 일어나고 있는지 자각하지 못하는 자동 조정 (automatic pilot) 상태에 관하여 토론하고, 이러한 상태에서 빠 져나오기 위해 자신의 주변으로 의도적으로 주의와 초점을 옮 기는 연습을 한다. 이를 위해 건포도 명상과 바디 스캔을 실시 한다(첫 회기에서 먹기 명상을 바로 실시하는 것은 일상생활에 서 흔하게 발생하는 자동 조정 상태를 깨닫게 하기 위함이다). 2 회기에는 바디 스캔과 정좌 명상을 통해 일상에서 일어나는 마음의 소리에 대한 반응을 조절하는 능력을 기른다. 3 회기는 문제를 풀어내야만 한다는 사고를 내려놓고 문제와 '함께 머무 는 방법에 관하여 접근한다. 이를 위해 정좌 명상과 호흡 명상, 걷기 명상을 실시한다. 4 회기의 주제는 현재에 머물기이다. 내적 인 불쾌함에 대해서는 현재에 머무는 것이 재발을 막는 가장 좋 은 방법이기 때문이다. 이를 위해 정좌 명상 및 호흡 명상과 더 불어 보기 명상과 듣기 명상을 실시한다. 또한 이 회기에서 the Diagnostic and Statistical Manual of Mental Disorders, Fifth Edition에 근거한 우울증의 진단 준거를 살펴보고 우울증 관련 체크 리스트를 실시하여 우울증을 탐구해 보는 시간을 갖는다. 5 회기의 주제는 수용하기이다. 이는 내가 삶에서 경험하는 것 들과의 관계를 긍정적으로 바꾸는 단계이다. 6 회기는 사실과 생각과의 차이에 대하여 탐구한다. 고통스러운 생각이 일어나 더라도 현실이 아닌 생각에 불과하다는 점을 깨닫고 이를 체득 하는 단계이다. 7 회기의 주제는 나 자신을 돌보기이다. 우울증 재발의 신호가 온다면 먼저 호흡 명상을 하고, 그 다음 무엇을 할지 결정하도록 하여 자신을 위한 시간을 갖도록 한다. 8회기 에서 지금까지 배운 것을 복습하고, 규칙적인 마음챙김 명상을 통해 삶의 균형을 유지하도록 돕는다.
Figure 1. Intervention content by session of the Korean version of the Mindfulness-Based Stress Reduction program.

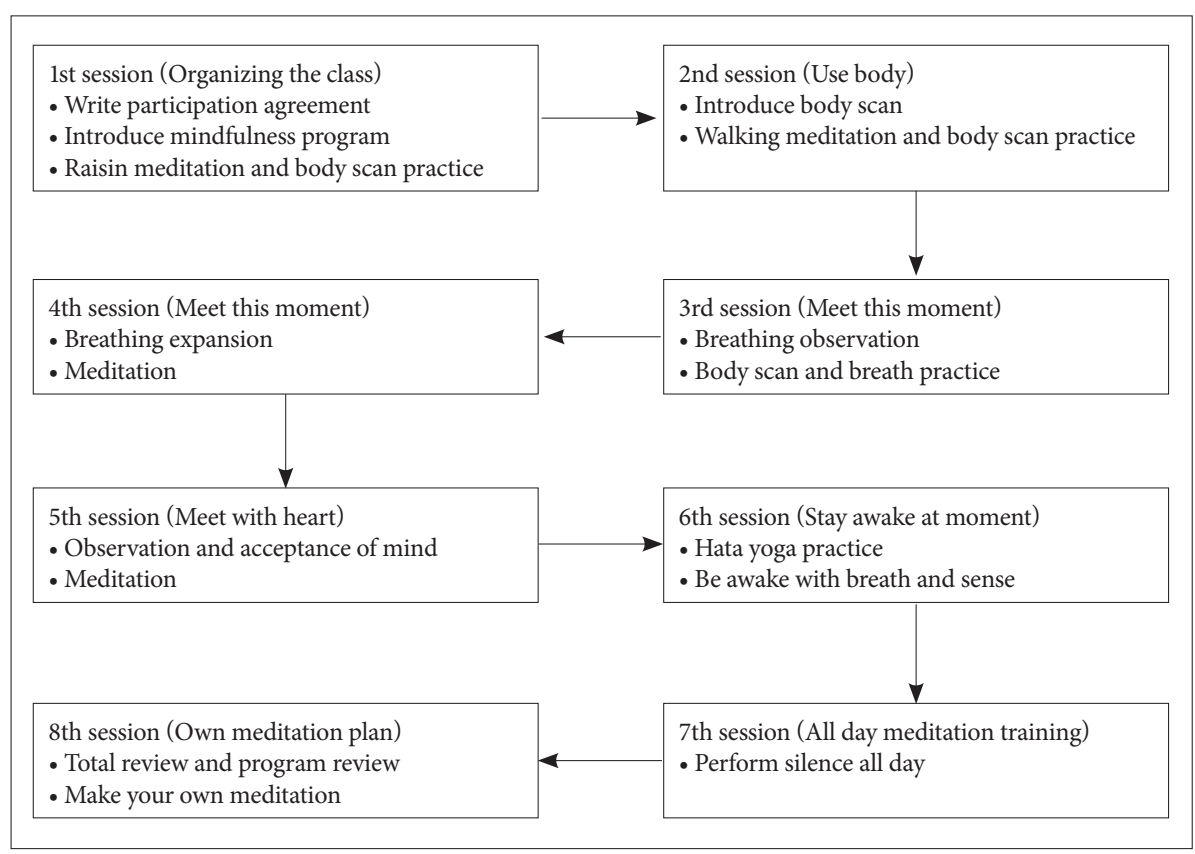


DBT

DBT는 Linehan(1993)이 경계선 성격장애인의 정서적 안정 과 자살행동의 감소를 위해 개발한 치료법이다. 국내에서는 청 소년의 공격성, 자아존중감 및 분노 표현방식에 대해 적용한 Jin $\& \operatorname{Son}(2013)$ 의 연구, 정서지능이 낮은 대학생을 대상으로 적용 한 Choi \& Son(2014)의 연구들이 있다. 이 치료법은 특히 정서 적 도피 및 회피 행동이 정신병리의 핵심이라고 가정하고 정서 적 고통의 수용에 초점을 맞춰 중재를 실시한다. 변증법이라는 용어는 모순 또는 대립되는 생각이나 사상 간의 균형과 통합을 의미하는데, 행동치료에서 이 용어는 인간이 경험하는 삶에서 경쟁적이고 모순적인 여러 요구, 기대, 욕망으로 인한 좌절에서 균형과 타협점을 제시하는 것이라고 할 수 있다. DBT는 마음챙 김 기술(mindfulness skills), 대인관계 효율성 기술(interpersonal effectiveness skills), 감정 조절 기술(emotion regulation skills), 고통 감내 기술(distress tolerance skills)의 네 가지 기 술 증진으로 이루어진다. 마음챙김 기술은 $\mathrm{DBT}$ 에서 가장 중요 하게 다루는 기술이다(Marra, 2005). 바디 스캔, 요가, 호흡 관 찰 등을 통해 자신의 인지, 정서 및 행동적 사건을 객관적으로 살펴보고 인식하게 되어 적절한 행동을 취하도록 한다(Marra, 2005). 대인관계 효율성 기술은 자신의 생활에서 대인관계 능 력을 향상시키도록 돕기 위한 기술이다(Linehan, 1993). 이를 위해 부정적인 결과를 만들어 낼 수 있는 대인관계 패턴을 살펴 보고, 자기주장 및 거절하는 방법, 타협하는 방법 등을 배운다. 감정 조절 기술은 자신의 감정을 확인하고 이를 효율적으로 다 루고자 하는 기술이다(Van Dijk et al., 2013). 이를 위해 일상생 활에서 감정 조절이 어려운 상황들을 분석하여 자신의 감정을 들여다보고, 감정과 반대되는 행동을 해 보며 더 효과적인 방 법으로 자신의 감정을 관리하도록 한다. 고통 감내 기술은 고 통스러운 상황하에서도 올바르게 목적을 추구하고자 하는 데 목적이 있다(Linehan, 1993). 고통스러운 상황의 회피를 막고 정서적인 반응을 수용하기 위해 주의를 다른 곳으로 돌리거나 마음챙김 기술을 사용하며, 고통을 유발하는 환경을 자신이 변화시킬 수 있는 방법에 대해 고찰한다.

\section{ACT}

ACT는 Hayes에 의해 개발된, 흔히 제 3 의 물결이라고 불리 는 인지행동치료의 새로운 모델이다. Acceptance는 수용으로 번역되고 commitment는 전념으로 번역된다. 그리고 줄임말 $\mathrm{ACT}$ 는 치료의 실제적, 행동적 부분을 강조하는 역할도 한다. $\mathrm{ACT}$ 에서는 정신병리의 원인이 경험 회피에 있는 것으로 보고, 이에 대한 대안으로 수용을 제시한다. ACT의 목표는 심리적 유연성을 증가시키는 것이다. 인생에서 자신만의 가치 있는 목 표를 추구하도록 하고 삶에 만나는 여러 문제들에 의식적으로
올바른 선택을 할 수 있도록 유도한다. ACT에서 다루는 6 가지 핵심 과정을 살펴보면, 첫째, 수용은 지금 이 순간의 경험을 비 판단적이고 적극적으로 경험하는 것을 의미한다. 이때 수용을 체념과 구분하여 이해할 필요가 있다(Hayes et al., 1999). 체념 은 이 순간의 경험을 단지 인내하는 것으로 부정적 감정이 존 재할 공간을 적극적으로 허용하는 행동인 수용과는 구분해야 한다. 이러한 용어상의 혼란 때문에 수용을 '기꺼이 경험하기 (willingness)'로 번역하기도 한다. 둘째, 인지적 탈융합(cognitive defusion)은 언어적 사고에 자동적으로 융합되는 것에서 벗어나는 것이다. 이는 생각 안에서 바라보는 것에서 벗어나 생 각 자체를 바라보는 것이라 할 수 있다. 외적인 문제 해결에 있 어서 인지적 문제 해결 전략이 유용하지만 내적으로는 오히려 문제를 더 크게 만드는 경향이 있다. 이러한 심리적인 문제를 악화시킬 수 있는 인지적 융합에서 벗어나는 것에 목적이 있다. 셋째, 현재에 존재하기(being present)는 삶은 항상 지금-여기 에서 일어난다는 사실을 강조한다. 과거나 미래에 대해 고찰하 는 것이 유용할 때는 그렇게 하되 불필요하게 삶을 낭비하지 않고 지금-여기를 살도록 하는 과정이다. 넷째, 맥락적 자기 (self as context)는 사회적 맥락에 맞춰 고정되지 않는 유연한 자기감을 갖도록 하는 과정이다. 삶에서 만나는 사회적 상황에 맞는 다양한 역할들을 수행한다. 이러한 역할을 수행함에 있어 맥락적으로 올바른 자기감을 획득하는 것이 목표이다. 다섯째, 가치(value) 탐구하기는 자신만의 삶의 가치를 탐구하는 과정 이다. 자신의 가치를 추구하며 살아가는 것은 행복의 중요한 재 료가 된다. 그리고 궁극적인 가치는 목표를 달성하는 것에 있는 것이 아니라, 목표를 향해 나아가는 과정 그 자체에 존재한다. 여섯째, 전념 행위(committed action)는 자신의 가치와 관련된 구체적인 행위 패턴을 수립하는 과정이다. 자신의 가치를 구체 적으로 실천하는 방법을 탐색하고 가치를 달성하기 위한 구체 적인 방안을 세부적으로 수립한다. 그리고 이 여섯 가지 과정 은 개별적인 단계가 아니라 서로의 과정에 영향을 미치게 된다.

\section{RESULTS}

\section{마음챙김과 말더듬 치료}

앞서 살펴본 네 가지 프로그램들은 마음챙김이라는 기본 바 탕하에 서로 다른 측면으로 시작되었다. 정리하자면, MBSR의 경우 만성적인 질병을 가진 환자들의 스트레스 감소를 위해 시 작되었다. MBSR에서는 주로 명상을 실시하는데, 이는 마음챙 김을 실천하기 위한 방편들로 시행된다. 이는 스트레스 관련 질 병(stress related disorder)에서도 그 효과가 나타났는데, 대학 생의 정서반응성에 긍정적인 효과를 나타내었고(Bae, 2010), 암 환자의 혈압 및 삶의 질에도 효과를 나타내었다(Lee et al., 
2012). 이외에도 불안, 우울, 만성통증, 근 섬유통, 폭식장애, 불 면증 및 건선 등과 같은 피부병 치료에도 효과가 있다고 한다 (Chang et al., 2007). 말더듬 분야에서는 스트레스 감소 효과 자체에 주목하기보다 어떻게 스트레스 감소 효과가 나타나게 되었는지 살펴보는 것이 도움이 될 것이다. 마음챙김의 주된 목 적은 현재 순간을 비판단적으로 의식하기 위해 늘 깨어 있고자 하는 것이다. 이를 말더듬에 적용해 보면, 말더듬인에게 말더듬 은 존재하는 것이다. 만약 말더듬 성인이 내적으로 말더듬을 없애기 위해 노력하는 행위들을 멈춘다면, 그리고 비판단적으 로 말더듬을 수용할 수 있다면 말더듬의 여부와 상관없이 말더 듬에서 자유(stutter-free)로워질 수 있을 것이다. 이러한 원리 를 적용하여 말더듬 성인을 상담하는 방법은 스스로 내적으로 확대하여 재생산하는 말더듬 성인의 고통을 멈추게 할 수 있 다. 이렇게 할 수 있도록 하기 위해 마음챙김 명상 프로그램을 말더듬 치료에 적용하면 이는 말더듬 성인을 더욱 전체적으로 접근하는 한 가지 방법으로 기능하게 된다(Heo et al., 2016). 또한 좀 더 말더듬 자체에 초점을 맞춰 실시하기 위해 말더듬 순간에 대해 명상하고, 고의적으로 말을 더듬어 보고 이를 자 각해 보는 과정을 추가하는 것도 하나의 방법이다. Van Riper (1973)의 말더듬 수정법(Stuttering Modification Therapy)에서 도 이러한 과정이 있는데 치료사에 따라서는 말더듬 수정법과 도 연계하여 실시할 수 있을 것이다. 말더듬 치료를 하다 보면 대상자 혹은 치료사의 특성에 따라 치료의 주안점을 말더듬 행 동치료에 맞추는 경우가 있다. 그러나 이러한 경우라도 마음챙 김의 원리를 말더듬인에게 설명하는 과정을 거칠 필요가 있다. 단기적인 상담 시에는 마음챙김 명상을 구체적으로 실시하는 것보다, 이러한 원리를 말더듬 성인에게 이해시키고 스스로 적 용하도록 하는 데에 초점을 두는 일이 더 효율적일 것이다. 말 더듬 성인은 말더듬을 없애기 위해 끊임없이 내적으로 노력해 온 경우가 일반적이다. 이러한 노력이 크면 클수록 내적으로 더 욱 고통받아 왔을 것이므로 이러한 말더듬 성인에게는 마음챙 김이 더욱 큰 효과를 가져다 줄 가능성이 높다. 그리고 이 원리 를 말더듬인에게 체득시키기 위해 마음챙김 명상을 실천하도 록 하는 것이 유연한 상담을 진행하는 방법일 것이다. 마음챙김 의 최종 목표는 말더듬에 관하여 일상에서 마음챙김의 원리가 자연스럽게 스며들도록 하는 것이다.

$\mathrm{MBCT}$ 는 MBSR을 토대로 우울증 환자를 대상으로 개발되 었다. MBSR에서 실시하는 하타 요가가 빠진 대신 인지치료적 인 요소들이 추가되어 있다. 이는 스트레스 감소에 초점을 둔 $\mathrm{MBSR}$ 과는 달리 MBCT는 우울증 재발 방지에 초점을 맞춘 프로그램이기 때문이다. 1 회기에 자동 조정 상태에 대해 다루는 데, Teasdale et al.(2000)의 연구에서 세 번 이상의 우울증 삽화 를 가지고 있는 참여자들을 대상으로 일반적인 치료(treatment as usual)를 받은 환자(66\%)에 비해 MBCT를 받은 환자들은 절반 정도(37\%)의 재발률을 보였다고 한다. 그러나 두 번의 우 울증 삽화를 가진 사람들에게서는 유의한 차이가 나타나지 않 았는데(일반적인 치료 $31 \%, \mathrm{MBCT} 37 \%$ ), 이는 두 번의 우울증 삽화 환자의 경우 외부적 요인에 의한 재발이고 세 번 이상의 우울증 삽화를 가진 환자들은 재발 원인이 자동 조정에 의한 것이기 때문이라고 설명한다. 말더듬 또한 재발 사례가 빈번하 게 보고되기 때문에(Ingham, 1984), 향후 말더듬인들의 자동 조정 상태에 대한 연구를 통해 말더듬 재발에 관한 효과를 살 펴볼 필요가 있을 것이다.

DBT는 경계선 성격장애 환자들을 대상으로 개발되었다. $\mathrm{DBT}$ 에서의 마음챙김 기술은 다른 세 가지 기술 증진을 위한 밑바탕이 되는데, 특히 대인관계 측면에서 보다 성공적인 삶을 살아가도록 돕는다. DBT는 정서적인 문제들이 완전히 해결될 것이라는 희망을 제공하지 않는다. 대신에, 삶에서 만나는 도전 적인 과제들에 대해 좀 더 자유롭고 의식적으로 해결할 수 있 는 기술들을 갖게 하는 것이 목적이다. DBT의 가장 큰 장점은 한 개인의 감정 및 정서에 영향을 미칠 수 있는 여러 요소들에 다각적인 측면으로 접근한다는 점이다. 즉, $\mathrm{DBT}$ 는 삶에서 경험 하는 여러 문제들의 해결 능력을 증진시키기 위해 대인관계 효 율성 기술, 사회기술 능력 증진, 목표 중심의 대인관계 및 자기 주장 훈련을 실시한다. 그리고 대인관계에서 겪을 수 있는 내적 인 요소들에 관한 감정 조절이나 고통 감내에 대해서는 마음챙 김 기술을 이용한다(Linehan, 1993). DBT는 치료 대상자의 특 성에 따라 프로그램에서의 기술들을 유연하게 가져갈 수 있다. 말더듬 치료에서도 말더듬 한 개인이 겪는 고통에 다각적으로 접근할 필요가 있는데, 말더듬 그 자체의 행동치료뿐만 아니라 필요하다면 대인관계 효율성 기술 등을 접근해 볼 수 있을 것 이다. 그러나 결국 궁극적인 목표는 자발적인 유창성이기 때문 에, 대상자에게 마음챙김 기술을 가르친 후 말더듬과 나와의 관계를 고찰해 보는 것이 우선일 것이다. 그리고 필요하다면 대 인관계 능력 향상에 관한 내용을 중재 프로그램에 추가할 수 도 있을 것이다.

$\mathrm{ACT}$ 는 심리적인 유연성을 증가시키기 위한 맥락적, 실제적 인 상태의 수용과 가치 실천을 강조한다. 그리고 이를 위해 명 상의 실천과 더불어 상담 시 수많은 메타포를 이용한다. ACT 의 궁극적인 목표는 심리적 유연성 증가이고, 말더듬 치료의 궁극적인 목표는 자발적인 유창성이라고 볼 수 있다. ACT에서 는 내면과 외면적인 문제들을 구분하여 어떻게 이 문제를 해결 해 나갈 것인지 탐구한다. 말더듬 또한 내면과 외면적인 문제가 공존하기 때문에(Van Riper, 1982), ACT에서 사용한 전략들 을 말더듬 문제 해결에 초점을 맞춰 변형할 수 있을 것이다. $\mathrm{ACT}$ 에서는 외면적인 문제 해결을 위해 가치 탐구, 전념 행위, 
맥락적 자기, 현재에 존재하기의 과정을 거친다. 말더듬 치료에 서는 말더듬 행동치료와 더불어 전념 행위, 현재에 존재하기를 사용할 수 있을 것이다. 전념 행위는 말더듬인이 일상생활에서 시행할 과제와 연관 지어, 말더듬을 해결하기 위한 실제적인 목 표 및 행동양식을 설정하는 것으로 대치할 수 있다. 현재에 존 재하기는 말더듬 및 말더듬이 유발하는 생각과 감정에 올바르 게 대처할 수 있도록 자동 조정 상태에서 벗어나는 데 활용할 수 있다. 또한 말더듬 행동의 자기 모니터링 효과도 가져올 수 있을 것이다. ACT에서 내면적 문제 해결을 위해 수용, 인지적 탈융합, 현재에 존재하기, 맥락적 자기의 과정을 거친다. 말더듬 치료에서 수용은 말더듬과 끓임없이 만나는 과정으로 사용할 수 있다. 고통스러운 감정을 회피 또는 제거하려는 시도는 실제 로는 고통을 증가시키게 되는 것이 사실이다(Eifert \& Heffner, 2003; Hayes et al., 1999). 이러한 시도들이 성공하지 못한 경우, 새로운 문제 해결 전략으로 수용을 제시하는 것이다. 이를 ACT 에서는 창조적 절망감 유발하기라고 표현한다. 인지적 탈융합 은 말더듬과 관련된 부정적 사고들에서 탈융합하는 방법으로 사용할 수 있을 것이다. 현재에 존재하기는 말더듬 순간을 비 판단적으로 의식하고, 말더듬과 관련된 내적 사건들을 수용하 기 위해 명상을 하는 과정으로 사용할 수 있을 것이다. 맥락적 자기감 갖기는 인지적 탈융합과 연계하여 말더듬과 상관없이 맥락적인 상황에 적합한 행동을 취하도록 하는 과정으로 사용 할 수 있을 것이다.

말더듬은 크게 겉으로 드러나는 행동과 내면화된 행동 두 가지로 나뉜다(Van Riper, 1982). 겉으로 드러나는 행동은 말 더듬 행동치료를 적용하면 줄어들 수 있을 것이다. 내면적인 특 징에서는 말더듬으로 인한 부정적인 요소들이 있다. 그리고 마 음챙김은 말더듬인의 내면적인 요소 및 도피, 회피 전략들에 관하여 중재하기 위한 방법으로 기능할 수 있을 것이다. 위의 내용들을 종합하여, 본 논문에서는 말더듬인에게 마음챙김에 기반한 상담을 실시할 때 필요한 과정을 3 단계로 구분하여 설 명하려 한다. 이 3 단계의 핵심 요소는 마음챙김의 원리인 현재 순간의 수용이다. 이를 위해 가장 먼저 해야 할 일은 $\mathrm{ACT}$ 에서 의 창조적 절망감 유발 및 $\mathrm{MBCT}$ 에서의 자동 조정 상태를 깨 닫도록 하는 것이다. 창조적 절망감 유발은 치료의 동기 유발에 해당된다. 자신의 상태가 어떠하고, 이에 관하여 지금까지 어떻 게 대처해 왔으며 어떠한 결과가 나타나는지 탐구한다. 예를 들 면, 상담 시 두꺼운 책이나 메모판 등을 말더듬으로 가정한다. 말더듬인에게 말더듬을 싫어하는 만큼 힘을 줘서 해당 물체를 밀어보고 또 숨겨 보라고 한다. 아무리 힘을 줘서 없애려고 노 력하고 숨기더라도 그 물체는 사라지지 않고 여전히 그 자리에 있다. 이는 말더듬인의 개인적 경험에 빗댈 수 있다. 지금까지 최선을 다해 말더듬을 해결하려고 시도해 왔던 개인적 전략들
이 정말로 말더듬을 해결해 주었는지 탐구하는 시간을 갖는다. 다음 자동 조정 상태에 관한 내용은 현재 자신이 어떻게 말더 듬에 반응하고 있는지 살펴보고, 향후 말더듬을 극복하기 위한 올바른 방향을 탐구해 나가는 것으로 첫 단계를 구성한다.

두 번째 단계는 올바른 방법을 탐구하는 단계이다. 지금까지 말더듬에 대처한 방법들이 오히려 상황을 악화시켰다는 것을 이해한 후, 대안적인 방법으로 수용을 제시하는 것이다. 한 가 지 주의할 점으로 말더듬 성인은 오랜 기간 말더듬에 도피, 회 피해 온 것이 일반적이다. 따라서 수용에 관하여 정확한 용어 로 설명할 필요가 있을 것이다. 수용은 수동적이고 소극적인 행위가 아닌, 지금 내 안에서 벌어지는 모든 것이 존재하도록 허용하는 적극적인 행위이다. 이 단계에서 치료사의 재량에 따 라 말더듬 수정법의 확인과 둔감화 단계를 덧붙여 실시할 수도 있다. 또한 ACT에서의 인지적 탈융합에 대해서도 추가적으로 다룰 수 있다. ACT에서의 인지적 탈융합을 그대로 적용한다면 말더듬의 경우 말더듬이 유발하는 생각 및 감정과 이에 융합했 을 때의 고통을 설명하고, 생각 및 감정과 탈융합하여 이를 객 관적으로 관찰하는 단계를 거치게 된다. 그러나 여기서는 인지 적 융합에 대하여 설명한 후, 이에 대한 대안으로 탈융합을 소 개하는 것이 아닌 그러한 생각과 감정을 적극적으로 만나는 수 용에 초점을 둔다. 이외에도 말더듬인에 따라 필요하다면 대인 관계 효율성 등의 요소들도 추가적으로 다룰 수 있을 것이다.

세 번째 단계는 수용을 구체적으로 실시하는 단계이다. 하루 1 시간씩 가정 혹은 기타 조용한 곳에 앉아 자신 안에 벌어지는 일들을 비판단적으로 있는 그대로 만나는 시간을 갖는다. 그리 고 ACT에서의 전념 행위 패턴 개발을 응용하여, 말더듬을 극 복하기 위한 전념 행위 패턴을 세부적으로 계획한 후 이를 실 천한 것을 치료 회기마다 과제로 제출하도록 한다. 글을 쓰는 것도 이 단계에서 할 수 있는 하나의 방법이다. 이때 글은 자신 의 내면에서 벌어지는 일을 판단하거나 조작하지 말고 정직하 게 써야 한다. 이 단계에서는 상담에 많은 시간을 할애할 필요 가 없다. 치료실 내원 시 수용 명상을 실천하고 있는지 여부만 확인하고 필요하다면 그에 관하여 코멘트하면 된다. 만약 대상 자가 앉아서 하는 명상을 어려워한다면 다른 마음챙김 명상인 걷기 명상, 호흡 명상을 해도 된다. 세 번째 단계가 끝나는 시기 는 대상자가 스스로 결정하도록 하되, 치료사는 대상자의 긍정 적 변화가 나타나는지 여부를 언어적·비언어적 메시지를 통해 관찰한다.

본 연구에서 앞서 설명한 세 단계를 Ryan(2001)이 제시한 말 더듬 행동치료 프로그램의 확립, 전이, 유지 단계와 결합하여 Figure 2에 제시하였다. 앞서 살펴본 마음챙김에 기반한 네 가 지 프로그램들에서 다륐던 심리치료적인 요소를 모두 포함하 기보다 말더듬을 해결하기 위한 올바른 방향이자 마음챙김의 
핵심인 내면적 요소의 수용(acceptance)에 초점을 두었다. Figure 2의 단계들을 따를 때 필요한 것은 첫 번째로 마음챙김 의 원리를 정확하게 이해하는 것이다. 마음챙김의 원리는 현재 순간을 비판단적으로 의식하는 것이다. 만약 현재 순간을 판단 하게 된다면 말더듬을 부정적, 잘못된 것으로 인식하게 되고, 이를 해결하려는 개인적 전략은 오히려 상황을 악화시키게 된 다. 두 번째로 필요한 것은 내담자와 함께 올바른 방향을 탐구
해 나가는 상담 기술이다. 치료사가 우위에 있고, 말더듬인에게 가르침을 주는 입장에 서는 것은 지양해야 할 필요가 있다. 치 료사는 조력자로서 상담 시 치료사가 상담을 이끌어나가는 것 이 아닌 말더듬인이 올바른 답을 찾도록 도와주고 함께 탐구해 나가는 역할에 머물러야 한다. 왜냐하면 결국 말더듬 치료는 말더듬인 스스로에게 달려 있기 때문이다. 세 번째로 각 단계에 서 올바른 방향으로 나아가는 데 도움을 줄 수 있는 자료들을

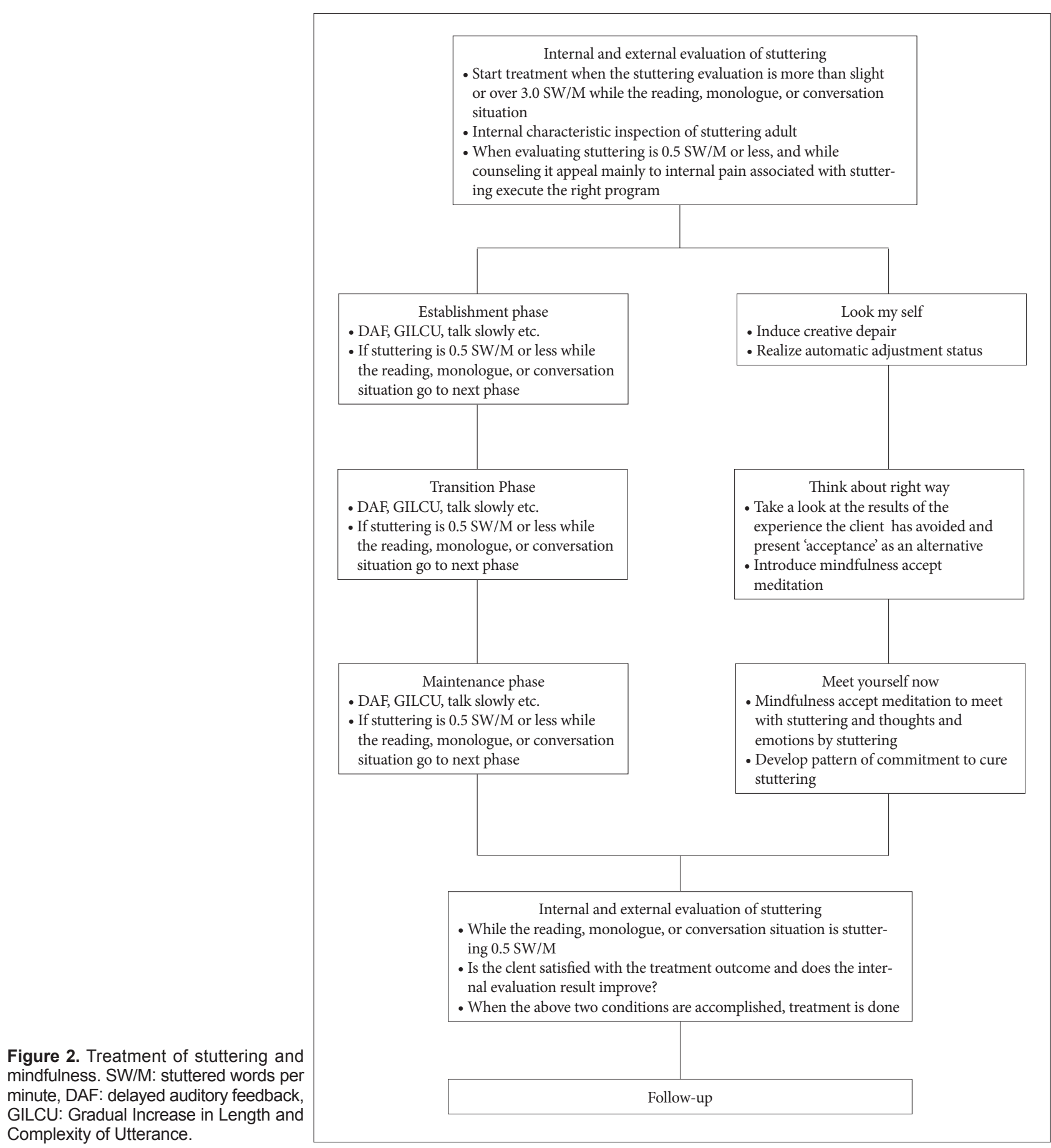


갖고 있어야 한다. ACT에서 다루는 수많은 메타포들을 적절히 활용한다면 도움이 될 것이라고 본다. 치료사의 경험이나 치료 예시들을 활용하는 것도 하나의 방법이다. 이외에도 대상자에 따라 대인관계 효율성과 같은 앞서 살펴본 4가지 프로그램들의 구성 요소들을 선택적으로 다룰 수도 있을 것이다. 말더듬 행 동치료와 마음챙김 상담의 시간 배분은 대상자의 특성에 맞춰 서 유연하게 실시할 필요가 있을 것으로 보인다.

\section{DISCUSSIONS}

현재 말더듬 행동을 줄이는 데 효과가 검증된 프로그램이 다수 존재한다. 그러나 말더듬 행동이 줄어들더라도 조절된 유 창성(controlled fluency) 수준의 말더듬인은 흔히 말을 할 때 빙판길을 걷는 것에 비유된다. 또한 말더듬 행동 자체도 재발이 빈번하게 나타나는 경우가 많다. 불안, 초조, 우울 등이 발생했 을 때 이를 없애려고 내적으로 노력한다면 상황은 더욱 악화될 가능성이 높아진다. 말을 더듬지 않으려고 내면적으로 노력하 는 것 또한 마찬가지이다. 이러한 상황에서 마음챙김은 하나의 효과적인 해결 방법을 제시하고 있다.

언어치료사가 말더듬 치료에 마음챙김을 적용하기 전에 한 가지 주의할 점으로, 마음챙김을 심리치료적인 목표에 중점을 둬서 사용할 필요는 없다는 점이다. 앞서 살펴본 4가지 마음챙 김 프로그램 중 교집합이 있다. 이는 명상을 실천하는 것이다. 명상을 실천하면 스트레스 감소 및 고요함, 평온함을 겪는 효과 가 나타나게 된다. Kabat-Zinn은 MIT 재학 시절 숭산 스님을 만나면서 마음챙김을 접하게 되었고, 많은 연구 끝에 MBSR을 개발하게 되었는데(Kabat-Zinn, 2006), 숭산 스님은 저서에서 이에 대해 다음과 같이 밝힌다(Seung, 2001). '심리치료와 참선 수행을 연결시키고 싶어 하는 사람들이 있다. 참선이나 명상을 하면 편안한 느낌을 갖기 때문이다. 순간적이라 할지라도 괴로 움이 모조리 사라지는 것 같은 느낌 말이다. 그러나 이것은 아편 과 같다. 수행 그 자체가 목적이 된다. 일상에서 사람들과 부대 끼며 일하려 하지 않고 다만 참선만 하려 한다. 그러면 수행과 삶은 분리된다. 참선을 특별한 것으로 만들어 버린다. 서쪽으로 가고 싶은데 동쪽으로 가는 셈이다. 선은 특별한 것이 아니다.

명상은 말더듬인이 말더듬에 직면하고 수용할 수 있게 하기 위해 실시하는 것이기 때문에, 명상하는 행위 그 자체에 의의 를 두는 것은 지양해야 한다. 명상을 실천하는 것은 마음챙김 이 지식적인 차원에 머무는 것을 넘어서 실용적으로 기능하도 록 하는 데 주 목적이 있고, 심리적으로 긍정적인 효과가 나타 나는 것은 오히려 부차적이라고 할 수 있다. 왜냐하면 자신의 있는 그대로를 만나는 이 행위조차 말더듬을 회피하는 수단으 로, 즉 수용을 하면 말을 더듬지 않게 되거나 고통받지 않을 수
있다는 식으로 생각할 가능성이 있기 때문이다. 이는 기저에 그러한 것을 회피하고자 하는 마음이 존재하는 것이다. 이때의 올바른 방법은 말더듬이 싫다는 감정이 내면에 있도록 있는 그 대로 허용하고 적극적으로 만나는 것이다. 그것으로 족하고, 오 히려 싫은 감정을 없애기 위해 노력하는 등으로 나아가지 않도 록 주의해야 한다. 다른 측면으로 살펴보면, 마음챙김을 적용해 나가는 과정은 고통스러운 과정이라고 표현할 수 있다. 말더듬 성인들은 말더듬이 싫기 때문에 도피 및 회피 전략들을 사용 하지만, 마음챙김에서는 만약 지금 이 순간 말더듬이 존재한다 면 이 말더듬을 회피하지 말고 직면하고 수용하도록 요구하기 때문이다. 말더듬을 단박에 낫게 해주는 마법의 알약 같은 것 은 존재하지 않는다. 말더듬을 해결하기 위해서 말더듬 성인은 말더듬이 유발하는 내적인 요소들에 끊임없이 직면해 나가야 할 필요가 있다. 마음챙김의 개념을 좀 더 넓게 살펴보면, 말더 듬인이 지금껏 겪어 온 말더듬과 관련된 고통 또한 마음챙김의 일종으로도 볼 수 있을 것이다. 누구라도 지금 이 순간을 벗어 나서 존재할 수는 없다. 그리고 한 개인이 겪은 내적인 고통이 크면 클수록 창조적 절망감 유발에 있어 더욱 큰 성과를 갖게 될 것이다. 따라서 현재 대부분의 말더듬 성인에게 마음챙김의 원리를 적용하기 위한 바탕은 이미 마련되어 있다고도 볼 수 있다. 비록 마음챙김이 불교에서 유래하였지만, 말더듬을 연구 하고 치료하는 사람들은 이 원리에 종교적으로 접근하는 것보 다 학문적, 치료적으로 접근하는 것이 옳을 것이다. 그리고 마 음챙김에서 설명하는 원리는 단순하다. 지금 이 순간을 바꾸기 위해 내적으로 다투면 다툴수록 문제는 역설적이게도 더욱 커 지게 된다. 삶의 나침반이라고 할 수 있는 마음챙김은 이러한 문제를 해결하기 위한 올바른 방향을 가리키고 있다.

중심 단어 : 말더듬 성인·마음챙김·내면적 특성·말더듬 치료.

\section{REFERENCES}

Bae, J. H. (2010). Effects of K-MBSR program according to the length of the training period on emotional response of college students. The Journal of the Korea Contents Association, 10(11), 198-208.

Beilby, J. M., Byrnes, M. L., \& Yaruss, J. S. (2012). Acceptance and commitment therapy for adults who stutter: Psychosocial adjustment and speech fluency. Journal of Fluency Disorders, 37(4), 289-299.

Boyle, M. P. (2011). Mindfulness training in stuttering therapy: A tutorial for speech-language pathologists. Journal of Fluency Disorders, 36(2), 122-129.

Chang, H. K., Kim, J. M., \& Bae, J. H. (2007). The development of Korean version of mindfulness-based stress reduction program and the effects of the program. The Korean Journal of Health Psychology, 12(4), 833850.

Cho, Y, J. (2016). The development the mindfulness real-intense communication program: The effects on teacher's mindfulness, teachers' efficacy and teachers-students relationship (doctoral dissertation). Changwon National University, Changwan.

Choi, C. R. \& Son, C. N. (2014). Effects of Dialectical Behavior Therapy (DBT) 
skill training on emotional intelligence, interpersonal problems, and mental health in college students with low levels of emotional intelligence. Korean Journal of Psychology, 19(2), 469-487.

De Veer, S., Brouwers, A., Evers, W., \& Tomic, W. (2009). A pilot study of the psychological impact of the mindfulness-based stress-reduction program on people who stutter. European Psychotherapy, 9(1), 39-56.

Eifert, G. H. \& Heffner, M. (2003). The effects of acceptance versus control contexts on avoidance of panic-related symptoms. Journal of Behavior Therapy and Experimental Psychiatry, 34(3-4), 293-312.

Guitar, B. (1998). Stuttering: An Integrated Approach to Its Nature and Treatment. (2nd ed.). Baltimore, MD: Lippincott Williams and Wilkins.

Hayes, S. C., Strosahl, K. D., \& Wilson, K. G. (1999). Acceptance and Commitment Therapy: An Experiential Approach to Behavior Change. (1st ed.). New York, NY: Guilford Press.

Hayes, S. C., Wilson, K. G., Gifford, E. V., Follette, V. M., \& Strosahl, K. (1996). Experimental avoidance and behavioral disorders: A functional dimensional approach to diagnosis and treatment. Journal of Consulting and Clinical Psychology, 64(6), 1152-1168.

Heo, D. R., Kwon, D. H., \& Kim, H. S. (2016). The effect of communication interventions based on acceptance and commitment therapy on the inner characteristics and stuttering behavior of adult stutterers. Journal of Speech-Language and Hearing Disorders, 25(1), 23-36.

Ingham, R. J. (1984). Stuttering and Behavior Therapy: Current Status and Experimental Foundations. San Diego, CA: College-Hill Press.

Jang, H. J. \& Kwon, D. H. (2005). The effect of behavioral cognitive stuttering therapy program on stutter and self-concept to adult stutterers. Journal of Speech and Hearing Disorders, 14(2), 193-203.

Je, S. H. (2016). The influence of mindfulness to place attachment, quality of experience and emotional solidarity in rural tourism villages (doctoral dissertation). Kyonggi University, Suwon.

Jeon, H. S. \& Kwon, D. H. (2005). A study on the effect of self-enhancement on adult stutterer's speech behaviors. Journal of Speech and Hearing Disorders, $14(4), 37-56$

Jeon, M. A. (2010). The therapeutic process of mindfulness-based cognitive therapy for emotion regulation: Grounded theory study (Doctoral dissertation). Yeungnam University, Gyeongsan.

Jin, D. S. \& Son, C. N. (2013). Effects of Dialectical Behavioral Therapy (DBT) skills training on aggression, self-esteem, and anger expression of adolescents. Korean Journal of Clinical Psychology, 32(4), 917-933.

Kabat-Zinn, J. (1982). An outpatient program in behavioral medicine for chronic pain patients based on the practice of mindfulness meditation: Theoretical considerations and preliminary results. General Hospital Psychiatry, 4(1), 33-47.

Kabat-Zinn, J. (2003). Mindfulness-based interventions in context: Past, present, and future. Clinical Psychology: Science and Practice, 10(2), 144156.

Kabat-Zinn, J. (2006). Coming to Our Senses: Healing Ourselves and the World Through Mindfulness. (2nd ed.). New York, NY: Hyperion Books.

Kim, S, Y. \& Kwon, D. H. (1994). The effect of stuttering therapy for gradual increase in the degrees of difficulty of utterance program. Journal of Speech and Hearing Disorders, 4, 1-18.

Ko, Y. O. \& Kwon, D. H. (2010). The characteristics of anxiety and attitude based on severity of stuttering. Journal of Speech and Hearing Disorders, 19(1), 99-118.
Kwon, D. H. \& Lee, I. S. (2004). The efffect of stuttering therapy based on slow speech on the fluency in adult stutters. Communication Disorder, 27(2), 167-178.

Lee, J. Y. (2016). The effects of airline cabin crew mindfulness on burnout, job satisfaction and customer orientation (doctoral dissertation). Soonchunhyang University, Asan.

Lee, W. J., Jun, J. S., Kim, Y. S., \& Gim, W. S. (2012). Effects of Korean Mindfulness-Based Stress Reduction (K-MBSR) on the blood pressure, psychological symptoms and quality of life in Korea cancer patients. The Korean Journal of Stress Research, 20(1), 1-9.

Linehan, M. M. (1987). Dialectical behavior therapy for borderline personality disorder. Theory and method. Bulletin of the Menninger Clinic, 51(3), 261-276.

Linehan, M. M. (1993). Cognitive-Behavioral Treatment of Borderline Personality Disorder. (1st ed.). New York, NY: Guilford Press.

Marra, T. (2005). Dialectical Behavior Therapy in Private Practice: A Practical and Comprehensive Guide. (1st ed.). Oakland, CA: New Harbinger Publications.

Plexico, L. W. \& Sandage, M. J. (2011). A mindful approach to stuttering intervention. Perspectives on Fluency and Fluency Disorders, 21(2), 43-49.

Ryan, B. P. (2001). Programmed Therapy for Stuttering in Children and Adults. (2nd ed.). Springfield, IL: Charles C Thomas Publisher.

Ryan, B. P. \& Ryan, B. V. K. (1995). Programmed stuttering treatment for children: Comparison of two establishment programs, through transfer, maintenance, and follow-up. Journal of Speech, Language, and Hearing Research, 38(1), 61-75.

Segal, Z. V., Williams, J. M. G., \& Teasdale, J. D. (2002). Mindfulness-Based Cognitive Therapy for Depression: A New Approach to Preventing Relapse. (2nd ed.). New York, NY: Guilford Press.

Seung, S. (2001). The Compass of Zen. (2nd ed.). Seoul: Yolimwon Publishing Group.

Sheehan, V. M. (1986). Approach-avoidance and anxiety reduction. In Shames, G. H. \& Rubin, H. (1st ed.). Stuttering: Then and Now. Westerville, OH: Merrill Pub Co.

Son, H. B. (2018). The effects of the Mindfulness-Based Cognitive-Behavioral Therapy (MBCT) program on loss of control, craving, mindfulness level in self-regulation of smartphone addictive tendencies (master's thesis). Kyungpook National University, Daegu.

Tan, C. M. (Trans. Kwon, O. Y.) (2012). Search Inside Yourself. Seoul: alkey.

Teasdale, J. D., Segal, Z. V., Williams, J. M., Ridgeway, V. A., Soulsby, J. M., $\&$ Lau, M. A. (2000). Prevention of relapse/recurrence in major depression by mindfulness-based cognitive therapy. Journal of Consulting and Clinical Psychology, 68(4), 615-623.

Van Dijk, S., Jeffrey, J., \& Katz, M. R. (2013). A randomized, controlled, pilot study of dialectical behavior therapy skills in a psychoeducational group for individuals with bipolar disorder. Journal of Affective Disorders, 145(3), 386-393.

Van Riper, C. (1973). The Treatment of Stuttering. (1st ed.). Englewood Cliffs, NJ: Prentice Hall Inc.

Van Riper, C. (1982). The Nature of Stuttering. (2nd ed.). Englewood Cliffs, NJ: Prentice Hall Inc.

Williams, J. M. G. (2008). Mindfulness, depression and modes of mind. Cognitive Therapy and Research, 32, 721-733. 